\title{
Incorporating Self Efficacy and Subjective Norms into the Integrated TAM/TTF to Evaluate Drivers of Corporate Career Portals and Users' Performance
}

\author{
Dr Hayel T. Ababneh ((corresponding author) \\ Department of Business Administration \\ Faculty of Economics and Administrative Sciences \\ Al Al-Bayt University, Hashemite Kingdome of Jordan \\ E-mail: hayelababneh@aabu.edu.jo
}

Dr Hasan Aleassa

Faculty of business studies

Arab Open University, Kuwait

E-mail: haleassa@aou.edu.kw

Received: August 23, 2018 Accepted: Sep 13, $2018 \quad$ Published: October 1, 2018

doi:10.5296/jmr.v10i4.13692 URL: https://doi.org/10.5296/jmr.v10i4.13692

\begin{abstract}
The goal of this research is to understand how recruiters perceive the fit between the characteristics of electronic job marketplaces and their needs, and how that fit influences the use of corporate career portals and expected performance. This paper contributes in providing considerable attention of technological, individual and social factors; thus, it integrates TAM and TTF and incorporates subjective norms and computer self-efficacy into the integrated model. This unique model is developed to interpret recruiters' attitudes towards its actual use, and consequently to understand the expected performance. A total of 145 valid responses collected from HR practitioners at Jordanian banks were statistically analysed. Results showed a good fit between the model's technological attributes and the task of recruiting. Thus, the results indicated that the proposed model could be used to predict the users' intention toward corporate career portal. The Actual use of corporate career portals was
\end{abstract}




\section{Macrothink}

Journal of Management Research

ISSN 1941-899X 2018, Vol. 10, No. 4

directly affected by perceived usefulness and subjective norms, while there was no effect of perceived ease of use on actual use. Indirectly, fit of technology characteristics to task requirements, and computer self-efficacy have a significant effect on actual use and ultimately on users' performance.

Keywords: TAM, TTF, Corporate career portal, Computer self-efficacy, Subjective norms 


\section{Introduction}

Electronic job marketplaces have been widely used due to the value added by their services for both employers and job seekers. Based on the task-technology fit (TTF) model, this study examines the impacts of task, technology and users' characteristics on individual performance while using corporate career portals (CCPs). To present a more accurate picture of potential outcomes, the actual utilization of CCP services must be considered, so the technology acceptance model (TAM) is also invoked to address the influence of users' perceptions of the usefulness and ease of use of CCPs. The study investigates how these combined drivers can interact with each and affect the actual use of CCPs and their users' performance.

TAM is a supportive model for explaining the main determinants of technology use and can be considered an effective tool for predicting potential use of technology, but it cannot determine what diverse factors can affect performance or how. Additionally, the actual use of information systems does not fully guarantee the desired performance. On the other hand, TTF predicts that when technology features accord with task requirements, users' performance will be at its highest level. However, there is no certainty in this prediction, so a greater amount of utilization will not necessarily lead to better performance. Thus, in order to reveal the diverse factors affecting actual use and performance, and because the two models (TAM and TTF) are related, interdependent and cannot be considered separately, it seems very useful to integrate them.

According to the theory of reasoned action (TRA), it is important to include social factors when interpreting the behaviour of information system users. Several researchers have argued that social influence is essential in determining user behaviour. Thus, it seems vital to study subjective norms, which have been neglected in both TAM and TTF. In response to calls by several authors (Mun \& Hwang, 2003; Chau, 2001; Compeau \& Higgins, 1995), this study also includes computer self-efficacy to make the model a more powerful predictor of system use.

\section{Theoretical Background}

\subsection{Corporate Career Portals}

Electronic job marketplaces have been extensively used by recruiters due to their ability to offer a perfect environment for companies searching for inaccessible candidates by advertising available positions, accepting resumés and taking applications over the Internet (Ababneh \& Shrafat, 2014; Dafoulas et al., 2003). Some companies rely on specialized websites to fill job vacancies, while larger companies build their own CCPs on their websites as a way of trimming recruiting costs and reducing the time needed to fill vacancies. Additionally, Turban et al. (2015) claim that electronic job marketplaces have other benefits over traditional job markets, such as faster and less expensive context updating, more space for details, superior ability of employers to find applicants, better matching of supply and demand, greater reliability, faster communication and wider reach to overseas applicants. For recruiters, the main functions of the electronic job marketplaces are to post job ads, give online interviews, review interviews and take interview feedback. 


\subsection{Task Technology Fit}

The TTF model assumes that when technology characteristics meet the requirements of the tasks to be accomplished, a fit will occur which may determine the extent of utilisation and performance (Goodhue \& Thompson, 1995). Thus, to improve the outcomes of its use, technology must be well suited to task requirements. TTF evaluates how individual performance varies with how compatible the technology is with the task being performed, according to Goodhue and Thompson (1995), who developed a measure of the fit between task and technology comprising eight factors: quality, locatability, authorization, compatibility, ease of use/training, production timeliness, systems reliability and relationship with users.

\subsubsection{Task Characteristics}

A task is widely defined as a piece of work assigned to be done, while task characteristics are "the aspects of a specific function required to accomplish an intended goal" (Goodhue, 1995). Three properties that differentiate tasks from each other were identified as variety, equivocality and interdependence (Goodhue 1995; Goodhue \& Thompson, 1995). The more varied and unpredictable a task, the more information is required to perform it. This requires HR professionals to rely on information systems for the purpose of acquiring timely information to address unexpected recruiting issues. Therefore, the following hypothesis was developed:

H1: Task characteristics are positively related to perceived task-technology-fit.

\subsubsection{Technology Characteristics}

A study conducted by Rogers (1995) found that five technology characteristics affected adoption: relative advantage, compatibility, complexity, trialability and observability. More specifically, Parry and Wilson (2009) argue that the adoption of commercial jobs boards is affected by two factors: compatibility and positive beliefs/relative advantage. Thus, not all benefits could be guaranteed, because electronic job marketplaces vary in terms of technology characteristics and in particular, how well the website or portal is designed. Dafoulas et al. (2003) assert that well developed electronic job marketplaces must be characterised by ease of use, navigability, system and layout consistency, efficiency of services and functions, communication quality, system availability, accessibility and low response time. According to Goodhue (1995), technology characteristics directly affect how users perceive the match between the technology and their needs. Thus, the following hypothesis was developed.

H2: Technology characteristics are positively related to perceived task-technology-fit.

\subsubsection{Task-Technology-Fit}

Based on the work of Goodhue (1995), fit is used to measure the level at which a specific technology matches a user's personal needs. Task-technology fit occurs when the functionality of the e-recruitment system meets task targets and individual abilities. From the perspective of Mathieson and Keil (1998), fit refers to the extent to which a particular 
technology assists in performing task effectively and efficiently, while for Klaus et al. (2003), fit stands for the match or congruence between an information system and its organisational environment. The following hypotheses were developed from the above arguments:

H3: Perceived task-technology-fit is positively related to perceived usefulness.

H4: Perceived task-technology-fit is positively related to perceived ease of use.

\subsection{Technology Acceptance Model}

Based on TRA, as developed by Fishbein and Ajzen (1975), TAM was elaborated to predict the intention to use technology. It is considered one of the most powerful tools for evaluating intention to use and the potential for actual use. Many researchers have used TAM in an effort to determine users' acceptance of technological applications such as health information systems (Pai \& Huang, 2011), mobile banking (Lee et al., 2007), online learning (Liu et al., 2010), cloud computing (Ababneh, 2016), digital libraries (Chen et al., 2016), e-commerce (Gefen \& Straub, 2000), social networking services (Kwon \& Wen, 2010) and many other applications of information technology (IT). TAM provides strong evidence that technology features alone cannot guarantee a specific level of use, because users' behaviour must also be considered. Thus, perceived ease of use and perceived usefulness are included as factors in TAM to improve insight into successful use of technology.

\subsubsection{Perceived Ease of Use and Perceived Usefulness}

Perceived ease of use is defined as "the degree to which a person believes that using a particular system would be free of effort" (Davis, 1989). Many studies (e.g. Venkatesh et al., 2003; Venkatesh \& Bala, 2008) assume that acceptance and use of technology will increase with users' perception of ease of use and usefulness. Others argue that technology cannot be perceived as useful unless users perceive it as easy to use. They will not see a tool as an effective intermediary for improving performance if they do not consider its use to be effortless. Then, once users perceive a technology as useful, they will be more inclined to use it (Davis, 1989; Davis, 1993). Thus, the following hypotheses are proposed:

H10: Perceived ease of use is positively related to perceived usefulness.

H11: Perceived ease of use is positively related to the extent of actual use.

H12: Perceived usefulness is positively related to the extent of actual use.

\subsubsection{Actual Use and Performance}

Based on TRA (Ajzen \& Fishbein, 1977), some studies have investigated the association between attitude and behaviour (Bagozzi 1982). According to TTF (Goodhue \& Thompson, 1995) the model assumes that users are more inclined to use IT which improves job performance. Fuller and Dennis (2009) found that fit is a reliable predictor of performance; teams with better fitting technology performed better than teams using poor-fitting technology.

H13: Level of actual use is positively related to the level of performance achieved. 


\subsection{Computer Self-Efficacy}

A survey conducted by Igbaria and Chakrabarti (1990) shows that the attitudes of users is directly affected by the interface between them and the system. The construct of self-efficacy (Compeau \& Higgins, 1995) represents how confident users are in their abilities while using computers. As defined by Bandura (1986), self-efficacy is the self-judgment on one's capability to follow a course of action required for a specific level of performance. This means that skills and ability are two distinct constructs and that the possession of skills does not guarantee the required level of performance without adequate belief in one's ability to utilise these skills to execute a particular task. Accordingly, performance in using new technology depends on the strength of the user's perceived confidence in his or her abilities. Compeau and Higgins (1995) argue that people enjoy tasks that they believe themselves able to perform masterfully. In information systems studies, it was found that users felt preparedness to use or self-efficacy to be related to willingness to adopt IT and to use it (Wang et al., 2015; Compeau \& Higgins, 1995). Consequently, the following hypotheses are developed:

H5: Computer self-efficacy is positively related to perceived usefulness.

H6: Computer self-efficacy is positively related to perceived ease of use.

\subsection{Subjective Norms}

In social cognitive theory (Bandura, 1986), actions are regulated by normative influences through social sanctions and self-sanctions. Behaviours that harmonise with social norms are well accepted by other people and elicit positive social reactions, while behaviours that violate social norms are criticised and provoke social censure. Social norms play two roles: as behavioural standards and as a self-regulatory system. According to social cognitive theory, people's attitudes are derived from observing the behaviour of others. Thus, people evaluate and correct their behaviour according to social standards. Therefore, the following hypothesis is developed:

H7: Subjective norms are positively related to actual use.

According to TRA (Fishbein \& Ajzen, 1975) and the subsequent theory of planned behaviour (Ajzen 1991), subjective norms will directly influence individual behaviour. Fishbein and Ajzen (1975) define a subjective norm as a "person's perception that most people who are important to him think he should or should not perform the behaviour in question" (p. 302). Parry and Wilson (2009) found that subjective norms, negative beliefs and positive beliefs/ relative advantage had a significant effect on adopting online recruitment through corporate websites. Based on the above arguments, the following hypotheses are developed:

H8: Subjective norms are positively related to perceived usefulness.

H9: Subjective norms are positively related to perceived ease of use.

\subsection{Proposed Model}

In accordance with the literature reviewed above, this study proposes a model with nine 
validated constructs (Figure 1), which are task characteristics, technology characteristics, computer self-efficacy, subjective norms, task-technology-fit, perceived usefulness, perceived ease of use, actual use and performance impact. The constructs of attitude and behavioural intention in TAM are excluded here because they are embedded in the construct of actual use. In other words, users will not use technology unless they already have positive attitudes towards its use and a real intention to use it. TAM is integrated with TTF as a response to many studies calling for the incorporation of the strengths of diverse technology adoption models (Dishaw \& Strong, 1999; Shih \& Chen 2013). Although TAM and TTF are useful models in explaining why people use IT, other human and social variables should be included (Legris et al., 2003; Ababneh \& Shrafat, 2014). Thus, subjective norms is added to the existing model, because users may encourage others to use computing technologies (Davis et al., 1989) and more particularly to achieve better results in attracting people to fill vacancies. As to computer self-efficacy, this supplements the current model in an attempt to discover how individual characteristics (Davis et al., 1989; Dishaw et al., 2002; Strong et al., 2006) may enhance perceived ease of use and usefulness, which in turn may have an effect on actual use and ultimately on overall performance.

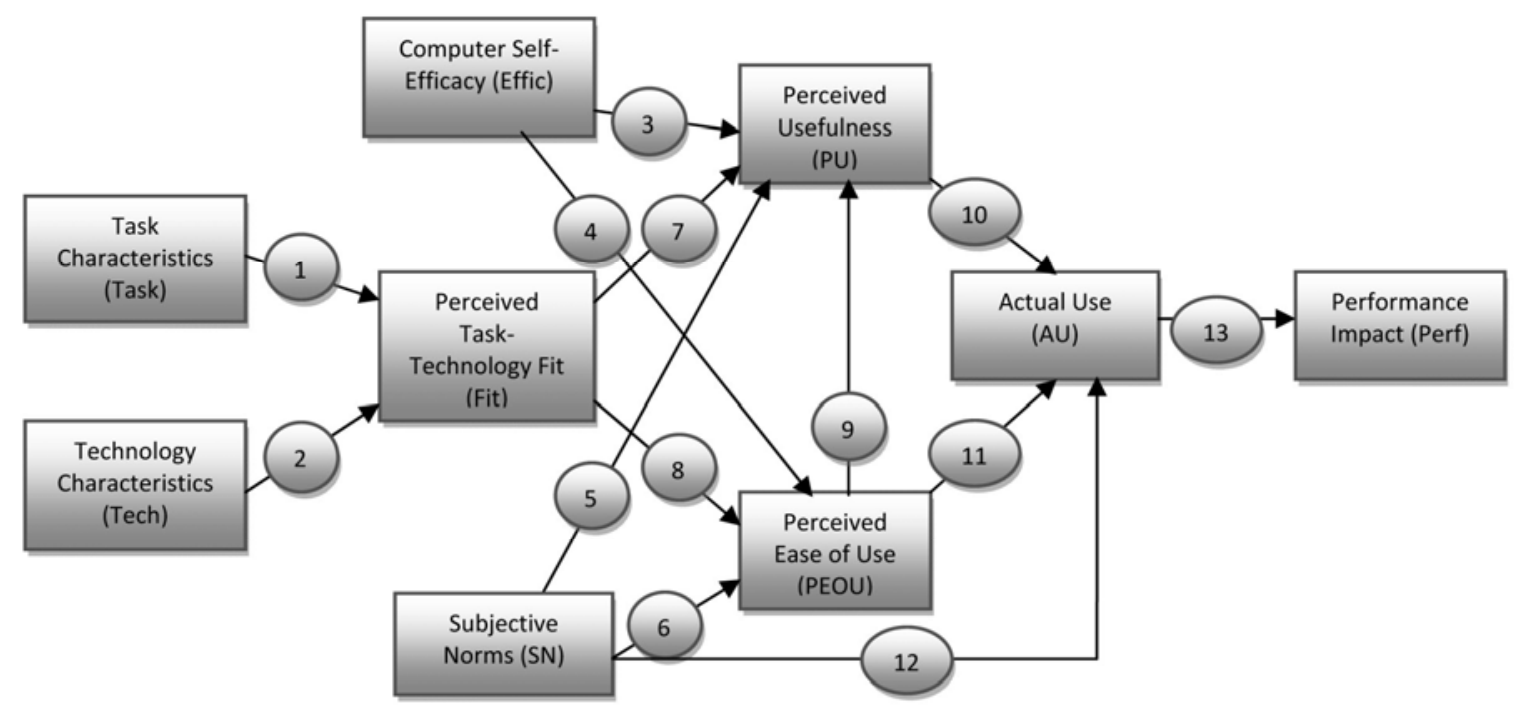

Figure 1. The extended TAM/TTF model

\section{Method}

\subsection{Data collection}

A survey was used to collect data from HR practitioners in the Jordanian banking sector. A total of 296 questionnaires were distributed in December 2016 with letters asking recipients to participate in this research. By the end of January, a total of 145 responses had been quantitatively analysed after discarding 24 invalid responses. Thus, the effective response rate was $49 \%$. The survey contained no means of identification and all responses were treated 
confidentially. The questionnaire had two sections: the first recorded the demographic variables of gender, age, schooling and job position, while the second investigated respondents' perceptions of each variable in the model. Data were collected using a five point Likert-type scale. All items are reproduced in the appendix.

\subsection{Respondent Profile}

Table 1 lists the demographics of the sample, which comprised 76 men (52.4\%) and 69 women (47.6\%). A majority of the respondents (68.3\%) were between 20 and 29 years old. Most (73.1\%; $\mathrm{n}=106)$ were HR practitioners, while 18 (12.4\%) were HR directors and 21 $(14.5 \%)$ were HR unit managers. The data indicate that a majority $(71 \%)$ of respondents held a college or university qualification.

Table 1. Sample demographics

\begin{tabular}{rlrll}
\hline Measure & & Items & Frequency & Percentage \\
\hline Gender & & Male & 76 & 52.4 \\
& & Female & 69 & 47.6 \\
Age & $20-29$ & 99 & 68.3 \\
& $30-39$ & 36 & 24.8 \\
& $40+$ & 10 & 6.9 \\
Schooling & High school & 18 & 12.4 \\
& College or university & 103 & 71.0 \\
& Advanced degree & 24 & 16.6 \\
Position & HR director & 18 & 12.4 \\
& HR unit manager & 21 & 14.5 \\
& HR practitioner & 106 & 73.1 \\
Note: $\mathrm{N}=145$ & & & \\
\hline
\end{tabular}

\section{Assessment of measurement model fit}

For the purpose of measuring fit for the extended TAM/TTF model, reliability and construct validity tests were conducted. Additionally, overall model fit was evaluated.

\subsection{Reliability}

To evaluate the internal consistency of the measurement model, the collected data were tested for reliability using composite reliability (Table 2). The model included 40 items describing nine constructs: subjective norms, perceived ease of use, perceived usefulness, task characteristics, technology characteristics, task technology fit, actual use, self-efficacy and performance impact. The composite reliabilities of the items included in the model ranged from 0.83 to 0.92. As recommended by Bagozzi et al. (1991), all reliability measures must exceed 0.60; thus, the reliabilities for all constructs in the proposed model are considered acceptable. 
Table 2. Means and standard deviation (SD) of research variable

\begin{tabular}{rrrrr}
\hline Variable & $\begin{array}{c}\text { Number } \\
\text { of items }\end{array}$ & Mean & SD & Alpha \\
\hline Subjective norms & 5 & 3.62 & 0.94 & 0.90 \\
Perceived ease of use & 4 & 3.78 & 0.87 & 0.83 \\
Perceived usefulness & 7 & 3.76 & 0.86 & 0.91 \\
Task characteristics & 4 & 3.72 & 0.88 & 0.85 \\
Technology characteristics & 6 & 3.64 & 0.94 & 0.92 \\
Task technology fit & 4 & 3.67 & 1.03 & 0.89 \\
Actual use & 3 & 3.62 & 1.00 & 0.88 \\
Self-efficacy & 4 & 4.12 & 0.90 & 0.89 \\
Performance impact & 3 & 4.02 & 0.94 & 0.84 \\
Note: $n=145$ & & & & \\
\hline
\end{tabular}

\subsection{Construct validity}

The two measures of discriminant and convergent validity were used to verify construct validity. Discriminant validity is used to make sure that the model constructs are divergent and not highly correlated. To ensure the discriminant validity of the model constructs, the square root of the average variance extracted (AVE) from the construct should be more than the correlation between the construct and any other construct (Fornell and Larcker, 1981). Table 3 shows that AVE (diagonal values) for each construct is larger than the inter-construct correlations. These satisfactory coefficients are considered to be sufficient to judge the discriminant validity of all constructs.

Table 3. Correlation matrix

\begin{tabular}{crrrrrrrrr}
\hline & \multicolumn{1}{c}{ SN } & PEoU & PU & Task & Tech & Fit & AU & Effic & PI \\
\hline SN & $0.881^{*}$ & & & & & & & & \\
PEoU & 0.660 & $0.756^{*}$ & & & & & & & \\
PU & 0.630 & 0.633 & $0.742^{*}$ & & & & & & \\
Task & 0.642 & 0.646 & 0.650 & $0.776^{*}$ & & & & & \\
Tech & 0.697 & 0.669 & 0.687 & 0.741 & $0.887^{*}$ & & & & \\
Fit & 0.752 & 0.703 & 0.726 & 0.532 & 0.845 & $0.944^{*}$ & & & \\
AU & 0.693 & 0.646 & 0.656 & 0.702 & 0.786 & 0.898 & $0.931^{*}$ & & \\
Effic & 0.498 & 0.396 & 0.395 & 0.435 & 0.495 & 0.551 & 0.509 & $0.803^{*}$ & \\
PI & 0.615 & 0.583 & 0.561 & 0.601 & 0.682 & 0.699 & 0.650 & 0.659 & $0.876^{*}$
\end{tabular}

Key: $\mathrm{SN}=$ Subjective norms; $\mathrm{PEoU}=$ Perceived ease of use; $\mathrm{PU}=$ Perceived usefulness; Task = Task characteristics; Tech $=$ Technology characteristics; Fit $=$ Task-technology fit; AU = Actual use; Effic = Self-efficacy; PI = Performance impact.

Note: Correlation is significant at 0.01 level (2-tailed).

$(*)$ values placed diagonally in the table express the discriminant validity

Furthermore, confirmatory factor analysis was used, as shown in Table 4, which lists the 
cross-loading of each item to its supposed construct. It shows that every single item was loaded higher on its attributed construct than on any other construct. This result indicates reasonable discriminant validity of the items included in the measurement tool.

Table 4. Confirmatory factor analysis and cross-loadings

\begin{tabular}{|c|c|c|c|c|c|c|c|c|c|}
\hline & \multicolumn{9}{|c|}{ Fact } \\
\hline & SN & PEoU & $\mathbf{P U}$ & Task & & Fit & $\mathbf{A U}$ & iffic & PI \\
\hline SN1 & .695 & .025 & .320 & $407-$ & & -.038- & -.026- & $-.174-$ & -.123 \\
\hline SN2 & & $-.115-$ & .186 & 363- & & $-.091-$ & .163 & 018 & 10 \\
\hline SN3 & .745 & .086 & .050 & $327-$ & $-.101-$ & .117 & $-.220-$ & $-.003-$ & .270 \\
\hline SN4 & .747 & .019 & .177 & .338- & $-.080-$ & $-.010-$ & $.001-$ & .035 & .205 \\
\hline SN5 & .844 & .004 & .054 & $-.228-$ & .025 & .008 & $-.164-$ & .083 & 098 \\
\hline PEol & 01- & 14 & .390 & $-.090-$ & -.028 & -.088 & $-.003-$ & .008 & -.244 \\
\hline PEoU2 & 09- & & .41 & .169 & $-.041-$ & -.254 & .245 & $-.154-$ & -.111 \\
\hline PEoU3 & $224-$ & & .101 & $-.179-$ & & .013 & .183 & -.076- & -.005 \\
\hline PEoU4 & $163-$ & .802 & -.148 & .040 & .271 & $-.243-$ & .013 & 010 & .056 \\
\hline PU1 & $\begin{array}{l}-.094- \\
\end{array}$ & & .772 & $-.127-$ & .314 & $-.022-$ & .069 & 53 & .113 \\
\hline PU2 & .317 & \begin{tabular}{|l|}
$-.294-$ \\
\end{tabular} & & .280 & $-.076-$ & .238 & .249 & .089 & .304 \\
\hline PU3 & .273 & $-.152-$ & & .325 & .14 & .298 & $-.117-$ & .147 & -.060 \\
\hline $\mathrm{U} 4$ & .190 & $-.080-$ & & .079 & .08 & .141 & .024 & $-.023-$ & -.005 \\
\hline PUS & .08 & & & .273 & .054 & $-.013-$ & .029 & .220 & .066 \\
\hline & & & & & & -..135- & & & \\
\hline $\mathrm{PU}^{\prime}$ & .109 & & & 157- & & $-.037-$ & 30 & & 012 \\
\hline Task1 & .061 & $-.210-$ & -.127 & .832 & .045 & .060 & $-.028-$ & $-.117-$ & $-.024-$ \\
\hline Task2 & .124 & -.168 & $-.150-$ & .841 & -.004 & .085 & $-.003-$ & .125 & -.132 \\
\hline Task3 & $\begin{array}{l}.075- \\
-\end{array}$ & $-.093-$ & & .729 & .12 & .082 & -.276- & $-.065-$ & -.201 \\
\hline & $-.428-$ & & & .699 & & -.268- & $-.165-$ & 021- & .178 \\
\hline & & & & & & -..103- & & & -.018 \\
\hline & - -.043- & & & .025 & & $-.054-$ & & .164 & $-.036-$ \\
\hline & .001 & $-.057-$ & -.06 & .031 & .87 & $-.091-$ & $-.164-$ & .100 & -.085 \\
\hline Tech4 & .161 & $-.087-$ & $-.076-$ & .102 & .82 & .120 & $-.039-$ & $-.273-$ & .101 \\
\hline Tech5 & .008 & $-.033-$ & & .108 & .83 & .018 & $-.254-$ & $-.161-$ & .028 \\
\hline & & & & 46 & & -..151- & & 07 & -.021 \\
\hline Fit1 & & & & .009 & & .805 & \begin{tabular}{|l|}
$-.097-$ \\
\end{tabular} & $-.130-$ & -.102 \\
\hline & & & $-.047-$ & .103 & -.199 & .838 & .057 & $-.185-$ & -.051 \\
\hline Fit3 & .222 & $-.090-$ & $-.134-$ & $-.138-$ & -.162 & .820 & .002 & $-.012-$ & -.162 \\
\hline Fit4 & .124 & $-.022-$ & $-.115-$ & $-.071-$ & -.326 & .785 & 053 & .255 & $-.010-$ \\
\hline AU1 & & & & $-.044-$ & $-.267-$ & .308 & 54 & .035 & .074 \\
\hline AU2 & .082 & $-.085-$ & $-.258-$ & $-.102-$ & $-.100-$ & -..011- & .825 & $-.241-$ & .012 \\
\hline & .06 & .009 & $-.207-$ & $-.002-$ & -.067 & .173 & .803 & $-.155-$ & .014 \\
\hline & & & -.078- & $-.125-$ & -.090 & .085 & .248 & .671 & $-.352-$ \\
\hline Effic2 & .107 & .737 & -.001- & $-.008-$ & .001 & .149 & $-.090-$ & .510 & $-.010-$ \\
\hline
\end{tabular}




\begin{tabular}{|l|r|r|r|r|r|r|r|r|r|}
\hline Effic3 & $-.051-$ & .706 & .011 & .065 & .143 & .106 & .025 & $\mathbf{. 5 8 1}$ & .047 \\
\hline Effic4 & $-.069-$ & .606 & .022 & .092 & .164 & .119 & .128 & $\mathbf{. 6 4 8}$ & .053 \\
\hline PI1 & .155 & .608 & .019 & .099 & .059 & $-.155-$ & .030 & $-.128-$ & $\mathbf{. 5 9 6}$ \\
\hline PI2 & $-.067-$ & .169 & $-.040-$ & .116 & .043 & $-.158-$ & .031 & .036 & $\mathbf{. 8 3 5}$ \\
\hline PI3 & $-.038-$ & .229 & $-.045-$ & .061 & $-.080-$ & $-.321-$ & .096 & .230 & $\mathbf{. 7 5 6}$ \\
\hline
\end{tabular}

Confirmatory factor analysis was also used to investigate convergent validity. The results in Table 4 indicate that all items had loadings above 0.50 on their particular constructs. This means that the measurement has adequate convergent validity (Hair et al., 2010).

\subsection{Evaluation of model fit}

For the purpose of evaluating the fit of the proposed model with the collected data, three fit indices were extracted as shown in Table 5.

Table 5. Overall fit indices of the research model

\begin{tabular}{|l|l|l|}
\hline Fit Index & Score & Recommended value \\
\hline Goodness-of-fit index (GFI) & 0.507 & More than 0.50 \\
\hline Adjusted GFI (AGFI) & 0.035 & Less than 0.05 \\
\hline Root mean square residual (RMSR) & 0.023 & Less than 0.05 \\
\hline
\end{tabular}

It is clear that the observed values fall within the recommended limits (Tabachnick and Fidell, 2007), meaning that the research model can be used to investigate the causal relationship between the different constructs and that no adjustment to the model is required.

\section{Model testing results}

Having assessed the overall model fit, the simple regression method was used to test the 13 proposed hypotheses. Table 6 shows that 12 of the 13 causal relationships were strongly significant at $\mathrm{p}<0.05$. 
Table 6. Results of hypothesis testing

\begin{tabular}{|c|c|c|c|c|}
\hline & Hypotheses & $\begin{array}{l}\text { Impact } \\
\text { value }\end{array}$ & $\begin{array}{c}\mathrm{p}- \\
\text { value }\end{array}$ & Results \\
\hline H1 & $\begin{array}{l}\text { Task characteristics are positively related to } \\
\text { perceived task-technology fit }\end{array}$ & 0.47 & 0.00 & Supported \\
\hline $\mathrm{H} 2$ & $\begin{array}{l}\text { Technology characteristics are positively } \\
\text { related to perceived task-technology fit }\end{array}$ & 0.56 & 0.00 & Supported \\
\hline H3 & $\begin{array}{l}\text { Perceived task-technology fit is positively } \\
\text { related to perceived usefulness }\end{array}$ & 0.46 & 0.01 & Supported \\
\hline $\mathrm{H} 4$ & $\begin{array}{l}\text { Perceived task-technology fit is positively } \\
\text { related to perceived ease of use }\end{array}$ & 0.32 & 0.00 & Supported \\
\hline H5 & $\begin{array}{l}\text { Computer self-efficacy is positively related } \\
\text { to perceived usefulness }\end{array}$ & 0.15 & 0.02 & Supported \\
\hline H6 & $\begin{array}{l}\text { Computer self-efficacy is positively related } \\
\text { to perceived ease of use }\end{array}$ & 0.36 & 0.00 & Supported \\
\hline H7 & $\begin{array}{l}\text { Subjective norms are positively related to } \\
\text { actual use }\end{array}$ & 0.12 & 0.01 & Supported \\
\hline H8 & $\begin{array}{l}\text { Subjective norms are positively related to } \\
\text { perceived usefulness }\end{array}$ & 0.32 & 0.00 & Supported \\
\hline H9 & $\begin{array}{l}\text { Subjective norms are positively related to } \\
\text { perceived ease of use }\end{array}$ & 0.45 & 0.00 & Supported \\
\hline H10 & $\begin{array}{l}\text { Perceived ease of use is positively related to } \\
\text { perceived usefulness }\end{array}$ & 0.43 & 0.00 & Supported \\
\hline H11 & $\begin{array}{l}\text { Perceived ease of use is positively related to } \\
\text { the extent of actual use }\end{array}$ & 0.22 & 0.06 & Not Supported \\
\hline H12 & $\begin{array}{l}\text { Perceived usefulness is positively related to } \\
\text { the extent of actual use }\end{array}$ & 0.32 & 0.00 & Supported \\
\hline H13 & $\begin{array}{l}\text { Level of actual use is positively related to the } \\
\text { level of performance achieved }\end{array}$ & 0.65 & 0.00 & Supported \\
\hline
\end{tabular}

It is clear that "perceived task-technology-fit" is affected by both "task characteristics" ( $\beta=$ $0.47, \mathrm{p}=0.00)$ and "technology characteristics" $(\beta=0.56, \mathrm{p}=0.00)$. Thus, H1 and H2 are supported. This implies that users of CCPs perceive this fit because they see that their tasks are diverse and changeable, and they also have positive feelings towards using a CCP. Thus, users increasingly perceive the fit between task characteristics and technology characteristics. In other words, users recognize that the CCP meets their task requirements. H3 and $\mathrm{H} 4$ were supported by a twofold significant impact of "perceived task-technology-fit" on "perceived usefulness" ( $\beta=0.46, p=0.01)$ and on "perceived ease of use" $(\beta=0.32, p=0.00)$. This means that becoming aware of the fit between task and technology increased their understanding of the CCP's ease of use and usefulness. Thus, users may consider CCPs to be good enough to recruit the required candidates. "Computer self-efficacy" was observed to have a significant impact on "perceived usefulness" $(\beta=0.15, p=0.02)$. Similarly, it was 
found to have a significant impact on "perceived ease of use" $(\beta=0.36, p=0.00)$. Therefore, $\mathrm{H} 5$ and H6 were supported. This result confirms that more self-confident users are more strongly motivated to use CCPs hopefully and simply. Hypotheses H7, H8 and H9 were supported because "subjective norms" had a significant impact on "actual use", "perceived usefulness" and "perceived ease of use" ( $\beta=0.12, \beta=0.32$ and $\beta=0.45 ; p=0.01, p=0.00$ and $\mathrm{p}=0.00$ respectively). Thus, users may change their perceptions according to the CCP use behaviour of others. The results also show that "perceived ease of use" had a significant positive impact on "perceived usefulness" $(\beta=0.43, \mathrm{p}=0.00)$; therefore, H10 was supported. However, it was unexpectedly found that "perceived ease of use" had an insignificant impact on "actual use" $(\beta=0.22, p=0.06)$, so that H11 was not supported. On the other hand, H12 was verified because the results show a significant positive impact of "perceived usefulness" on "actual use" $(\beta=0.32, p=0.00)$. This may indicate that maximising the level of CCP use requires increased awareness of its worth rather than its effortlessness. Finally, "actual use" had a positive impact on the level of performance achieved $(\beta=0.65, p=0.00)$. Consequently, H13 was supported. This indicates that the users' performance will be improved as long as the level of CCP use increases.

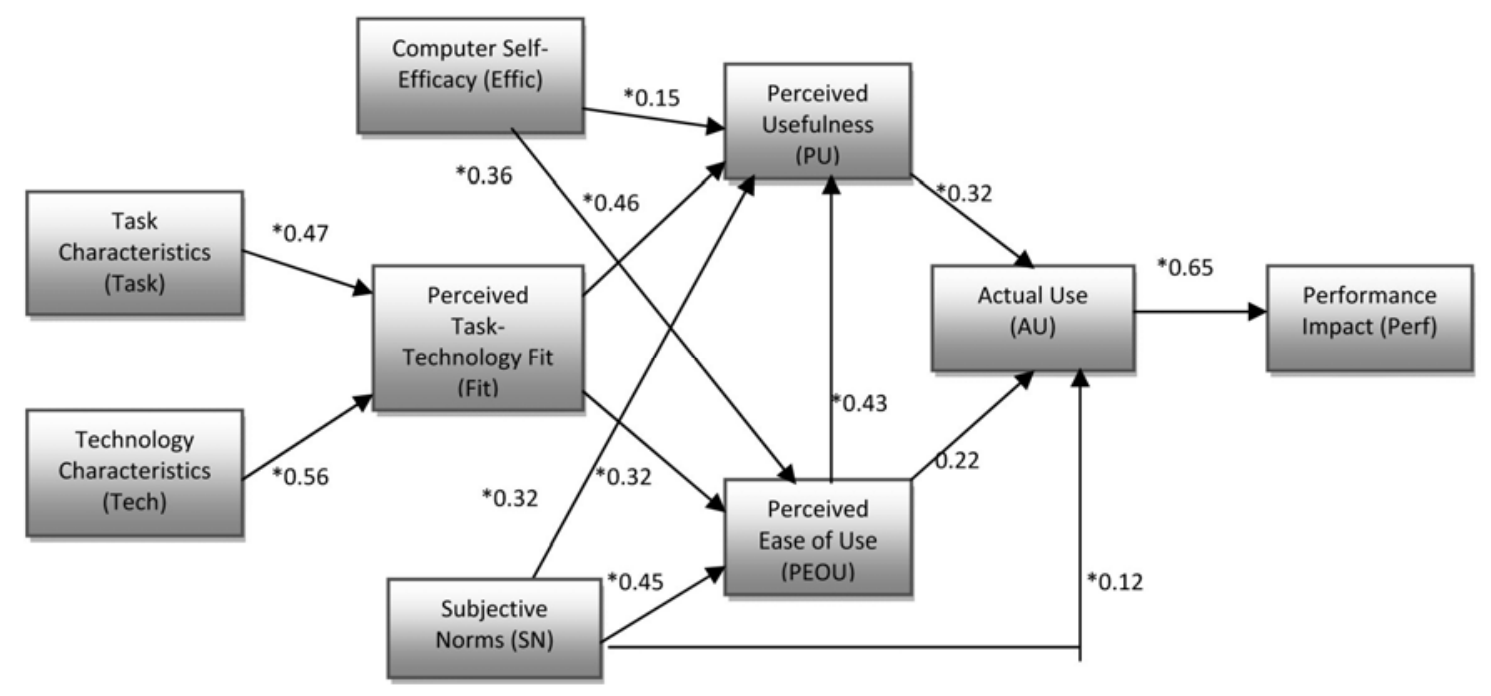

Figure 2. Measurement Model Results

\section{Discussion and Conclusion}

This study has successfully integrated TTF (Goodhue \& Thompson, 1995) with TAM (Davis, 1989) and extended them with the inclusion of two other drivers (subjective norms and computer self-efficacy) in the previously unexamined context of CCP use. The prevailing power of the current model lies in its comprehensive scope, as it includes organisational, social and individual factors (Park, 2009). Based on the model fit indices, the integrated model shows itself to be a powerful instrument to explain the intention to use a CCP. Empirical testing of the extended TTF-TAM found the model to be strongly supported, with only one insignificant hypothesis. Consequently, the extended TTF-TAM contributes to a better understanding of the drivers that lead to determining the extent of the actual use of a 
$\mathrm{CCP}$ and its expected level of performance.

It was found that when users perceive a fit between task characteristics and technology characteristics, they will perceive the usefulness of the CCP more than its ease of use. It was also noticed that perceived usefulness (PU) is greatly affected by subjective norms, while computer self-efficacy has the least effect on PU. Thus, more attention should be given to choosing the appropriate functionalities of the technology (CCP in this case) to fit the task being done. As to users' perception of ease of use, the results of hypothesis testing indicate that this is predominantly affected by computer self-efficacy and subjective norms. This points to the importance of improving users' self-confidence in their ability to use CCPs effortlessly and efficiently, as well as considering the persuasive effect of other CCP users on expectations of its ease of use. Actual use was found to be driven mainly by perceived ease of use and subjective norms, rather than perceived usefulness. Thus, vendors of such IT tools should focus on providing useful and worthwhile solutions which help users to perform their tasks well and to attain their intended goals. At the same time, IT developers must be aware of the need to persuade users that their CCP is easy to use. Finally, the results show that actual CCP use has a strong impact on users' performance.

The results imply that the interactions among individual qualities, job characteristics, technological features and collective relationships explain why HR professionals use CCPs at a specific level. Thus, more attention should be given to the determinant factors of CCP usage and its association with the required level of performance.

\section{Contribution to knowledge}

Because technology acceptance may vary in diverse cultural contexts, the impact of social and individual variables on technology adoption and usage needs more attention in studies addressing different social and individual attributes. Thus, the existing study incorporates "subjective norms" and "computer self-efficacy" with the two well-established research models (TAM and TTF) in an attempt to reach a better understanding of the roles of these variables in forming users' perceptions of the usefulness of corporate career portals and their ease of use, and ultimately the recruiters' actual usage and performance levels. This study examined directly how technology characteristics, task characteristics, subjective norms and computer self-efficacy influence individual performance by the mediation of perceived task-technology fit, perceived usefulness and perceived ease of use. In building and testing these hypothetical links, this study contributes to the literature by showing their significance to IT use.

The present research contributes to knowledge by formulating a model that overtly investigates the variables influencing actual CCP use and their interrelationships. Our results suggest that some aspects of CCP use are determined by users' perceptions of usefulness and by subjective norms. They are also indirectly affected by users' efficacy and by the fit between specific technology characteristics and specific needs of a task. I believe that current results provide a better appreciation of theory that depicts the process by which users adopt CCPs. 


\section{Contribution to Practice}

In practice, system vendors need to be more mindful that actual use entails developing a system which is more customisable to the specific requirements of the task being done. Members of IT support services should be aware that raising the level of use is determined not only by training and boosting computer skills but also by fostering users' confidence in their abilities to use such systems proficiently. Additionally, it is important to note that users' perceptions are affected by the attitudes of others, so managers should connect other individuals having positive attitudes towards a CCP with its potential users so that the former can communicate their positive attitudes, which may enhance the latter's perceptions of easiness, convenience and possible utility.

\section{Limitations and recommendations for future research}

This enquiry has some limitations which are applicable to any survey or field study. Another limitation arises from the means of selecting respondents, which lacked randomness. Targeting a single sector in Jordan makes it difficult to generalise our findings to other sectors. This study encourages other researchers to use samples from other service and manufacturing organisations around Jordan. It is hoped that this study will stimulate further research to examine the existing model in other contexts or extend it by incorporating other variables such as organisational norms and values, or wider environmental forces.

\section{References}

Ababneh, H. (2016). Extending the Technology Acceptance Model and Critical Success Factors Model to Predict the Use of Cloud Computing. Journal of Information Technology Research (JITR), 9(3), 1-17. https://doi.org/10.4018/JITR.2016070101

Ababneh, H. T., \& Shrafat, F. D. (2014). Analysing the role of culture in IS studies. International Business Research, 7(11), 165. https://doi.org/10.5539/ibr.v7n11p165

Ababneh, H. T., \& Shrafat, F. D. (2014). Human capital information systems: An introduction. International Journal of Business and Management, 9(9), 193. https://doi.org/10.5539/ijbm.v9n9p193

Ajzen, I., \& Fishbein, M. (1977). Attitude-behavior relations: A theoretical analysis and review of empirical research. Psychological bulletin, 84(5), 888. https://doi.org/10.1037/0033-2909.84.5.888

Bagozzi, R. P., Yi, Y., \& Phillips, L. W. (1991). Assessing construct validity in organizational research. Administrative science quarterly, 421-458. https://doi.org/10.2307/2393203

Bandura, A. (1986). Social foundations of thought and action: A social cognitive perspective. Englewood Cliffs, NJ: Princeton-Hall.

Bandura, A. (1986). Social foundations of thought and action: A social cognitive theory. NY.: Prentice-Hall.

Chau, P. Y. (2001). Influence of computer attitude and self-efficacy on IT usage behavior. 
Journal of Organizational and End User Computing, 13(1), 26. https://doi.org/10.4018/joeuc.2001010103

Chen, J. F., Chang, J. F., Kao, C. W., Kao,... \& Huang, Y. M. (2016). Integrating ISSM into TAM to enhance digital library services: A case study of the Taiwan Digital Meta-Library. The Electronic Library, $\quad$ 34(1), https://doi.org/10.1108/EL-01-2014-0016

Compeau, D. R., \& Higgins, C. A. (1995). Computer self-efficacy: Development of a measure and initial test. MIS quarterly, 19(2), 189-211. https://doi.org/10.2307/249688

Dafoulas, G. A., Nikolaou, A. N., \& Turega, M. (2003, January). E-services in the Internet job market. In System Sciences, 2003. Proceedings of the 36th Annual Hawaii International Conference on (pp. 9-12). IEEE.

Davis, F. D. (1989). Perceived usefulness, perceived ease of use, and user acceptance of information technology. MIS Quarterly, 13, 319-340. https://doi.org/10.2307/249008

Davis, F. D. (1993). User acceptance of information technology: System characteristics, user perceptions and behavioral impacts. International Journal of Man-Machine Studies, 38, 475-487. https://doi.org/10.1006/imms.1993.1022

Davis, F. D., Bagozzi, R. P., \& Warshaw, P. R. (1989). User acceptance of computer technology: A comparison of two theoretical models. Management science, 35(8), 982-1003. https://doi.org/10.1287/mnsc.35.8.982

Dishaw, M. T., \& Strong, D. M. (1999). Extending the technology acceptance model with task-technology fit constructs. Information \& Management, 36(1), 9-21. https://doi.org/10.1016/S0378-7206(98)00101-3

Dishaw, M., Strong, D., \& Bandy, D. B. (2002). Extending the task-technology fit model with self-efficacy constructs. AMCIS 2002 Proceedings, 143.

Fornell, C., \& Larcker, D. F. (1981). Evaluating structural equation models with unobservable variables and measurement error. Journal of marketing research, 39-50. https://doi.org/10.2307/3151312

Fuller, R. M., \& Dennis, A. R. (2009). Does fit matter? The impact of task-technology fit and appropriation on team performance in repeated tasks. Information Systems Research, 20(1), 2-17. https://doi.org/10.1287/isre.1070.0167

Gefen, D., \& Straub, D. W. (2000). The relative importance of perceived ease of use in IS adoption: A study of e-commerce adoption. Journal of the Association for Information Systems, 1(1), 8. https://doi.org/10.17705/1jais.00008

Goodhue, D. L. (1995). Understanding user evaluations of information systems. Management science, 41(12), 1827-1844. https://doi.org/10.1287/mnsc.41.12.1827

Goodhue, D. L., \& Thompson, R. L. (1995). Task-technology fit and individual performance. MIS Quarterly, 213-236. https://doi.org/10.2307/249689 
Hair, J. F. Black. WC, Babin., BJ, Anderson RE,(2010) Multivariate data analysis, a global perspective. New Jersey. Pearson. Ed, 7, 816.

Igbaria, M., \& Chakrabarti, A. (1990). Computer anxiety and attitudes towards microcomputer use. Behaviour \& Information Technology, 9(3), 229-241. https://doi.org/10.1080/01449299008924239

Klaus, T., Gyires, T., \& Joseph Wen, H. (2003). The use of web-based information systems for non-work activities: An empirical study. Human Systems Management, 22(3), 105-114.

Lee, K. S., Lee, H. S., \& Kim, S. Y. (2007). Factors influencing the adoption behavior of mobile banking: A South Korean perspective. The Journal of Internet Banking and Commerce, 12(2).

Legris, P., Ingham, J., \& Collerette, P. (2003). Why do people use information technology? A critical review of the technology acceptance model. Information \& Management, 40(3), 191-204. https://doi.org/10.1016/S0378-7206(01)00143-4

Mathieson, K., \& Keil, M. (1998). Beyond the interface: Ease of use and task/technology fit. Information \& Management, 34(4), 221-230. https://doi.org/10.1016/S0378-7206(98)00058-5

Mun, Y. Y., \& Hwang, Y. (2003). Predicting the use of web-based information systems: Self-efficacy, enjoyment, learning goal orientation, and the technology acceptance model. International Journal of Human-Computer Studies, 59(4), 431-449. https://doi.org/10.1016/S1071-5819(03)00114-9

Pai, F. Y., \& Huang, K. I. (2011). Applying the technology acceptance model to the introduction of healthcare information systems. Technological Forecasting and Social Change, 78(4), 650-660. https://doi.org/10.1016/j.techfore.2010.11.007

Park, S. Y. (2009). An analysis of the technology acceptance model in understanding university students' behavioral intention to use e-learning. Educational Technology \& Society, 12(3), 150-162.

Parry, E., \& Wilson, H. (2009). Factors influencing the adoption of online recruitment. Personnel Review, 38(6), 655-673. https://doi.org/10.1108/00483480910992265

Shih, Y. Y., \& Chen, C. Y. (2013). The study of behavioral intention for mobile commerce: Via integrated model of TAM and TTF. Quality \& Quantity, 7(2), 1-12. https://doi.org/10.1007/s11135-011-9579-x

Strong, D. M., Dishaw, M. T., \& Bandy, D. B. (2006). Extending task technology fit with computer self-efficacy. ACM SIGMIS Database, 37(2-3), 96-107. https://doi.org/10.1145/1161345.1161358

Tabachnick, B. G., \& Fidell, L. S. (2007). Using multivariate statistics. Allyn \& Bacon/Pearson Education.

Turban, E., King, D., Lee, J. K., Liang, T. P., \& Turban, D. C. (2015). Electronic commerce: A managerial and social networks perspective. Springer. 
https://doi.org/10.1007/978-3-319-10091-3

Venkatesh, V., \& Bala, H. (2008). Technology acceptance model 3 and a research agenda on interventions. Decision Sciences,

https://doi.org/10.1111/j.1540-5915.2008.00192.x

39(2),

273-315.

Venkatesh, V., Morris, M. G., Davis, G. B., \& Davis, F. D. (2003). User acceptance of information technology: Toward a unified view. MIS Quarterly, 27(3), 425-478. https://doi.org/10.2307/30036540

Wang, J. L., Jackson, L. A., Wang, H. Z., \& Gaskin, J. (2015). Predicting social networking site (SNS) use: Personality, attitudes, motivation and internet self-efficacy. Personality and Individual Differences, 80, 119-124. https://doi.org/10.1016/j.paid.2015.02.016

\section{Appendix. Questionnaire items}

\section{1) Subjective norms (SN)}

- My peers would think that using the career portal to recruit online is a wise idea.

- Our rivals would think that using the career portal to recruit online is a good idea.

- The culture of our industry is very much online

- Our existing employees seek jobs internally by looking into our career portal

- We use online recruitment to move with the times

2) Perceived ease of use (PEoU)

- My interaction with the corporate job portal is clear and understandable

- Interacting with the corporate job portal does not require a lot of my mental effort

- It is much easier than other recruitment methods

- I find our career portal is easy to use

3) Perceived usefulness (PU)

E-recruiting via corporate portal .....

- ... would improve my performance

- ... would help attracting qualified candidates

- $\quad$... could make it easier to contact with more applicants

- ... is an efficient way of recruiting people

- ... improves the diversity of applicants

- ... easy to attract the right candidates

- ... is faster to hire than any other method 


\section{4) Task Characteristics (Task)}

- I frequently deal with nonroutine recruiting issues that not predictable in advance

- The recruiting issues I deal with frequently involve more than one business function

- Frequently, I need on-time data to address emerged recruiting issues occur irregularly

- Frequently, after I see what the data say, I change my view of recruiting requirements and of what data are needed

\section{5) Technology Characteristics (Tech)}

Our corporate career portal is

- ... secure

- ... confidential

- ... available anytime

- ... easy to navigate

- ... reliable

- ... operates well technically

6) Task Technology Fit (Fit)

- The career portal satisfy our task needs

- The career portal is suitable for achieving our recruiting goals

- The career portal is sufficiently serve our recruiting responsibilities

- In general, our career portal is appropriate.

7) Actual use (AU)

- I prefer to use our career portal

- Primarily, I use our career portal to recruit applicants

- I intend to continue using our career portal in the future

8) Self-Efficacy (Effic)

Confidently, I could complete recruiting process using the career portal

- ... even no one around to tell me what to do as I go

- ... even I had never used a career portal like it before

- ... if I had only directing manuals for reference

- ... if someone else had helped me to get started 


\section{9) Performance Impact (PI)}

- The corporate job portal has a large, positive impact on my effectiveness and productivity in my job

- The use of corporate job portal is a good choice for recruiting potential candidates

- The online recruitment system is an important and valuable aid to me in the performance of my job 